\title{
Yurupari y el canon literario colombiano. Apuntes para una discusión sobre la interculturalidad ${ }^{56}$
}

\section{Yurupari and the Colombian literary canon. Notes for a discussion of interculturalism}

\author{
Fabio Gómez Cardona
}

Recibido: 20 de Agosto 2011. Aprobado: 15 de Septiembre 2011

\begin{abstract}
Resumen
El texto de Yurupari, recopilado por Max. José Roberto y preservado en su traducción al italiano por el Conde Ermano Stradelli, es la única obra de la tradición mítica amerindia que ha sido plenamente incorporada al canon literario colombiano hasta el momento. En este ensayo se examinan y discuten algunos aspectos relativos a esta obra y al complejo multimedial mítico y ritual del yuruparí, los problemas que genera su múltiple traducción lingüística y cultural, su significación y pervivencia en diversas versiones, entre distintos pueblos de la amazonía colombo-brasilera, y lo que autores relevantes, desde la antropología y desde la literatura, han escrito a propósito del libro.
\end{abstract}

Palabras clave: Pueblos indígenas de Colombia; Literatura indígena en Colombia; Yuruparí, Amazonia; Etnohistoria; Escritores indígenas; Mito; La Vorágine; José Eustasio Rivera, Heterogeneidad cultural; Interculturalidad.

\begin{abstract}
Yurupari text, compiled by Max. José Roberto and preserved in its Italian translation by the Conde Ermanno Stradelli, is the only work of the legendary Native American tradition that has been fully incorporated into the Colombian literary canon so far. This essay examines and discusses some aspects of this work and the mythical and ritual yurupari multimedia complex problems generated by its multiple linguistic and cultural translation, its significance and survival in several versions, among peoples of the Amazon colombo-Brazilian, and what relevant authors, from anthropology and from the literature, have written about the book.
\end{abstract}

Keywords: Indigenous Peoples of Colombia; Indian Literature in Colombia; Yuruparí, Amazonia, ethnohistory, Indian Writers, Myth, La vorágine, Jose Rivera Eustasio, cultural heterogeneity; Interculturalism.

Entre los textos de las escrituras amerindias en Colombia, el único que ha logrado un reconocimiento amplio y un estatus elevado por parte de la crítica literaria colombiana hasta alcanzar la dimensión de texto canónico es El Yuruparí, del indígena Max. José

\footnotetext{
${ }^{56}$ Ensayo resultado de la Investigación del autor, inscrita al grupo en Literaturas y Culturas Amerindias Mitakuye Oyasin de la Universidad del Valle.
} 
Roberto, traducido al italiano por el antropólogo Ermanno Stradelli, y retraducido luego al español por Susana N. Salessi.

El primero en llamar la atención sobre este texto fue el crítico Javier Arango Ferrer en 1959 y 1965. Según Héctor Orjuela, el texto fue traducido al español por el historiador Pastor Restrepo Lince, pero esta traducción permanece inédita y Arango Ferrer en sus estudios incluye fragmentos de la misma. No obstante, el investigador y crítico literario Héctor Orjuela, es quien mayormente ha contribuido para que El Yuruparí alcance un lugar memorable entre los estudios de la literatura indígena latinoamericana; en efecto, es a partir de los trabajos de Héctor Orjuela que el Yuruparí empieza a tener una acogida cada vez más favorable entre los investigadores de la literatura en Colombia, se lo compara con otras obras ya clásicas de las literaturas indígenas de América como el Popol-Vuh y el Ollantay y, llega a ser propuesto inclusive como el texto fundador de la literatura colombiana, cosa en mi parecer algo exagerada como vamos a ver, sin demeritar los valores propios de la obra.

El inicio del proceso para la inclusión del Yuruparí en el canon literario colombiano fue como ya hemos dicho la publicación por Javier Arango Ferrer, de un artículo aparecido en la revista Mito en 1959: Dioses, brujos y héroes precolombinos y en 1965 de la obra Raíz y desarrollo de la literatura colombiana. Pero es sólo hasta 1983 con la publicación por parte del Instituto Caro y Cuervo del libro del profesor Héctor Orjuela Yurupary: Mito, leyenda y epopeya del Vaupés, un importante estudio de la obra que incluye además la traducción del italiano al español, del relato del Yuruparí, realizada por Susana Salessi. Este trabajo fundamental de Héctor Orjuela se constituye en el punto de partida y referencia obligada de casi todo lo que posteriormente se ha escrito sobre el relato amazónico. Aparte de otras publicaciones menores sobre el tema, Orjuela, publicó en 1993 otro estudio titulado Yurupary. El Popol-Vuh suramericano. Otros trabajos significativos sobre el Yuruparí son el de Cecilia Caicedo de Cajigas, 1990, Origen de la literatura colombiana, el de Renata Sedláckóva (2000) El Mito amazónico de Yurupary como obra literaria, y entre los más esclarecedores y pertinentes a pesar de su brevedad, el de Betty Osorio 2006, El mito de Yurupary: Memoria ancestral como resistencia étnica; en el 2009 Elsa Cristina Posada escribió una bella e interesante monografía de 
Maestría en Literatura, Oralidades y Escrituras en el Amazonas Colombiano, donde hay una referencia permanente al Yuruparí.

Para el nivel de la educación media en Colombia, que nos interesa por cuanto tiene que ver con la difusión y la circulación masiva del texto y su incorporación paulatina en el imaginario cultural de los colombianos, es importante destacar que, Fernando Ayala Poveda en su Manual de literatura colombiana ( $1^{\mathrm{a}}$ edic. 1984 y $19946^{\mathrm{a}}$ edic.), incluye un primer capítulo sumamente breve Literatura viva aborigen, en el que dedica dos páginas al Yuruparí; otro tanto hace Isaías Peña Gutiérrez en su Manual de literatura

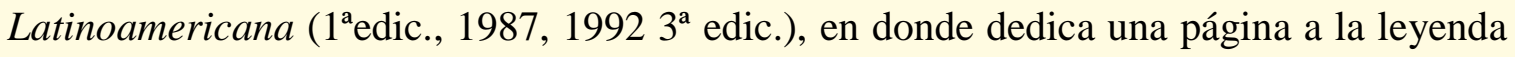
de Yurupary, en el capítulo inicial Literatura Aborigen. Otro texto escolar popular pero mucho mejor elaborado, el Manual de Literatura Colombiana de Procultura en dos tomos, ni siquiera menciona el tema indígena y presenta el inicio de la literatura con los cronistas y escritores coloniales. Finalmente, como una contribución a la difusión amplia de la obra es necesario destacar que en 1990 Cecilia Caicedo Cajigas hizo una edición popular con fragmentos seleccionados del texto y una breve introducción para la colección de cuadernillos de poesía Quinto Centenario, y en el año 2005, Panamericana, una editorial especializada en textos escolares, publicó, en su línea de literatura juvenil, una nueva traducción hecha por Beatriz Ángel, bellamente ilustrada, con una introducción explicativa sobre el origen y la historia de la "leyenda" y un glosario de vocablos indígenas utilizados en la obra.

Ahora bien, los estudios realizados sobre el Yuruparí se centran en la descripción formalista o estructuralista del texto, el análisis de sus ejes temáticos principales, y su comparación con otros textos de procedencia indígena en América, pero descontextualizan y deshistorizan el texto al mirarlo sólo como un objeto estético desligado de las condiciones de explotación, de aniquilamiento, de violencia contra los pueblos indígenas de la amazonía, que dominaban y seguramente incidieron en sus circunstancias de producción y traducción cultural originales como lo muestra Osorio (2006). Por mi parte, y en contradicción con la opinión de la misma Osorio en lo que toca a la relación entre Yuruparí y la literatura colombiana (canónica), en una investigación doctoral realizada entre el 2003 y 2008, Interculturalidad y violencia étnica en la literatura colombiana, he procurado demostrar, cómo hay una incidencia significativa de 
la mitología amerindia en algunas obras importantes de la literatura colombiana, v. gr. $L a$ vorágine, Andágueda y otras, y esta incidencia se manifiesta no solamente a nivel de las temáticas desarrolladas por las novelas sino que afectan su estructura misma la cual pareciera seguir las pautas míticas de los pueblos en cuestión.

Betty Osorio afirma que "el sistema mítico de Yurupary, hasta ahora, es totalmente ajeno a la tradición letrada colombiana"; y en su referencia a La Vorágine sostiene que...

José Eustacio Rivera, en su novela La vorágine (1924), dejó un testimonio poético sobre esta debacle cultural, aunque se preocupó más por la suerte de los blancos que por la de los indígenas que apenas son visibles en su relato. Las catedrales de la selva distancian, minimizan y convierten en emoción estética, el terrible sufrimiento vivido por los nativos. Un gran sector de la crítica de La vorágine ha seguido este camino, que a mi juicio evita así confrontaciones con la elite política e intelectual, que son funciones a menudo compartidas en la vida cultural colombiana.

En mi interpretación de la novela de Rivera, y tomando como referente diversas versiones de la mitología amazónica, principalmente, del Yuruparí y del Viaje de la Anaconda Sagrada, trato de mostrar cómo aunque el indio pareciera ocupar un lugar mínimo y marginal en la historia de La vorágine, esto se ve compensado con la "estructuración desestructurada" de la novela, la cual, en sus temáticas dominantes, en la articulación de sus episodios, en la visión de mundo que instaura, de manera consciente o no por parte del escritor, se rige por estos patrones míticos amazónicos, lo que en su momento le valieron a Rivera muchos reproches por parte de los críticos literarios que no veían una obra formalmente coherente según los cánones clásicos eurocéntricos de la composición novelística. (Gómez Cardona 2008 y 2010).

Lo cierto de todo es que cincuenta años después de su "descubrimiento" para el universo literario, Yuruparí ha alcanzado ya un lugar de prestigio en la literatura colombiana y se ha ido incorporando paulatinamente al canon hasta entonces reacio a conferir la más mínima importancia a las producciones textuales amerindias. Pero la historia de Yuruparí, no comienza con su inclusión dentro de la literatura colombiana y ni siquiera es un texto exclusivamente "literario"; como buena parte de la literatura latinoamericana y de la literatura producida por indígenas, el Yuruparí trae la impronta de la heterogeneidad cultural, lingüística, y está signado igualmente por la historia de universos culturales en colisión; es un producto híbrido, que ha llamado la atención de misioneros religiosos, 
antropólogos, viajeros, escritores, etc., y como las otras obras clásicas del mundo americano tiene una historia digna de ser recordada.

La historia de la operación transculturadora, de cómo un mito de la tradición oral amazónica se transformó en un texto fijado por escrito e incorporado al acervo de la literatura occidental ha sido reconstruida entre otros por Orjuela (1993), Sedláckova (2000), Pineda Camacho y Álzate Ángel (2005) y Osorio (2006), a quienes sigo en esta breve reconstrucción. Ya desde el siglo XVIII hay referencias al mito y al ritual de Yurupari por parte de misioneros y cronistas; durante el siglo XIX muchos viajeros, habían dado noticias e interpretaciones más o menos erróneas del mismo, asociándolo siempre con orgías sexuales y el culto diabólico; hacia 1879 llega por primera vez a territorio brasilero, el viajero italiano Conde Ermano Stradelli quien vivió cerca de 43 años en este país como "explorador, naturalista, geógrafo y etnólogo" (Orjuela, o.c., 32), haciendo varios viajes al Vaupés, logrando granjearse la amistad, la simpatía y el respeto de las tribus indígenas.

Stradelli recorrió el Vaupés tres veces: La primera en 1881, cuando llegó al río Tiquié y al Sapô. La segunda en 1882, en la que visitó Jauareté, pasando luego por el Apaporis hasta Piraquara. La tercera entre 1890 - 1891. Exploró cerca de 700 kilómetros de este territorio, más que Henri Coudreau, cuyas informaciones muchas veces son de segunda mano y no ofrecen la objetividad que tienen las de Stradelli. El italiano se sintió casi nativo de la región y llegó en un dabacurí (fiesta ceremonial), en la cachoerira Mirity, hasta el extremo de dejarse pintar el rostro por los indios y de bailar y beber chicha con ellos. Era conocido en numerosas tribus y fue uno de los pocos blancos a quienes se permitió viaje libremente por el territorio indígena cuando en 1882 se prohibió el comercio con los blancos. (Orjuela 1993)

Stradelli conoció diferentes versiones del mito y quería demostrar que en contra de lo que predicaban los misioneros y otros, este no tenía nada qué ver con un culto al demonio; fue entonces cuando conoció al autor del manuscrito de Yuruparí, Maximiniano o Maximino o Max, José Roberto. Antes que Stradelli, el naturalista brasilero Joâo Barbosa Rodríguez se había mostrado interesado en hacer una recopilación del mito de Yuruparí y contaba para esto con la colaboración de Max Roberto, pero el indígena antes que fungir como un simple informante y colaborador, emprendió por sí mismo la elaboración de un texto donde se unificaran versiones del mito procedentes de distintos grupos y lenguas, y lo redactó en lengua Ñeengatú, la lengua geral, de las tribus amazónicas, finalmente 
decidió entregar este manuscrito a Stradelli y no al naturalista brasilero, y el italiano pudo así traducirlo a su lengua y hacerlo publicar en su país.

Al parecer todos los etnógrafos que visitaron el Vaupés en las dos últimas décadas del siglo XIX lo conocieron y para algunos fue amigo, guía e informante insustituible en las expediciones por el noroeste amazónico brasilero. Con quien más congenió fue, sin embargo, con el Conde Stradelli, y fue a él precisamente a quien confió el manuscrito de la leyenda, prefiriendo dárselo al conde y no a Joâo Barbosa Rodríguez, quien se esforzó por conseguirlo. Era hombre culto y profundo conocedor de la cultura de sus antepasados, y recogió o ayudó a recopilar, numerosas leyendas que en ocasiones aparecieron en textos bilingües para cuya transcripción era indispensable su ayuda (Orjuela 1993, 29-30).

Las circunstancias de la vida de Maximino lo ubicaban en una situación privilegiada para emprender esta tarea. Era hijo de indios manaos por el lado paterno y su madre era una india tariana del río Vaupés; su madre era hermana del Tuixaua o cacique y por lo tanto él mismo podía ser considerado jefe espiritual; en casa de su abuela en Tarumâmiry, que era un sitio de paso para indios de numerosas tribus, podía recoger las leyendas de los distintos pueblos; además como es característico entre los pueblos amazónicos, era conocedor de diversidad de lenguas, cuyo rastro se puede seguir incluso a través de la traducción al italiano. Cuando en 1926, el conde Stradelli muere de lepra cerca de Manaos, sus objetos personales fueron quemados por orden de las autoridades y entre esos objetos el manuscrito original de Max José Roberto seguro fue destruido por el fuego. Sólo sobrevivió la traducción al italiano que había sido publicada en 1890.

A la muerte de Stradelli, los manuscritos originales en lengua geral, abigarrados seguramente con vocablos y expresiones cubeo, tucano o tariana, fueron quemados por las autoridades sanitarias de Manaos, celosas de extirpar toda huella de la lepra, sin que el conde hubiese podido cumplir su propósito de publicarlas en el idioma original. Pero, de manera similar al héroe de Yuruparí, que se incinera para que de sus cenizas renazcan las palmas con las cuales se fabrican las flautas del Yuruparí, el texto de Maximiano (que según Stradelli "he tratado de traducir lo más sencillo posible") renace día a día, como una pieza clásica de la cultura latinoamericana. (Pineda-Camacho y Álzate, 2004)

Vemos pues que en el proceso de traducción lingüística y cultural del texto de Yuruparí han intervenido múltiples factores asociados a las relaciones de interculturalidad no sólo de los pueblos amazónicos entre sí, sino también con la sociedad occidental. No obstante, uno de los aspectos más importantes como es el de las circunstancias conflictivas que se vivían en la Amazonía a raíz de la explotación cauchera, el genocidio contra los pueblos indígenas por parte de los empresarios occidentales, la virulenta violencia de los 
misioneros contra las sociedades indígenas y su espiritualidad, los procesos de organización, de resistencia, de franca rebeldía de los indígenas para preservarse física y culturalmente, han sido prácticamente dejados de lado por los estudiosos del Yuruparí. Betty Osorio (2006) es quien llama la atención sobre la importancia de este contexto histórico y su posible influencia entre las motivaciones del indio Max. Roberto para emprender esta múltiple traducción del texto de Yuruparí como una forma de preservación de la memoria de los pueblos y como un ejemplo más de resistencia histórica.

Ahora bien, siendo como es un relato mítico centrado en las acciones de un héroe cultural y dador de leyes, el mito de Yuruparí comparte muchos rasgos análogos, estructuras arquetípicas y simbólicas con mitos equivalentes de muy diversas culturas a nivel mundial, y no sólo con los héroes civilizadores mayas, aztecas, incas o muiscas, sino también griegos, egipcios, del oriente o del judeo-cristianismo, como se puede constatar siguiendo a Otto Rank o a Joseph Campbell; pero el análisis de las estructuras no aporta mayormente a la intelección de los mitos amerindios, si no está acompañado de las condiciones de actualización, producción y difusión de los textos, a las circunstancias sociales e históricas que hay detrás de las motivaciones, a sus contextos cultural e intercultural específicos. Como hemos visto en otros apartes de este trabajo, los mitos se constituyen en un baluarte ideológico, en una forma de resistencia, de preservación de un cierto nivel de autonomía política, económica, cultural de los pueblos indígenas frente al avasallamiento por parte de la sociedad occidental, y este es el caso también de la escritura del Mito de Yuruparí por parte de un indígena amazónico, en momentos en que se acentuaba la crítica situación de estos pueblos asolados por la voracidad y la rapiña que han alimentado al capitalismo mundial.

Examinemos ahora otros aspectos del mito: en primera instancia la complejidad que comporta el término mismo de "Yuruparî" y la inasibilidad conceptual que nos revela; empecemos para esto examinando lo que nos dice Héctor Orjuela en razón de que es el investigador más autorizado de nuestro texto, pero confrontémoslo también con otras voces no menos autorizadas:

El nombre de Yurupary (Yurupary, Jurupary, Iurupary, etc.) se origina de la lingua geral o ñengatú, derivada del tupí-guaraní que en una época se convirtió en lengua franca en las regiones del Vaupés, Isana y río Negro. Hay varias interpretaciones sobre el 
significado del nombre, pero las más difundidas son las que lo traducen como "engendrado de la fruta" o "boca sellada", aludiendo esta última acepción al silencio en que se mantiene lo relativo al culto, asociado en ciertas tribus con la figura de un demonio selvático, y en otras con la tradición de una deidad civilizadora que impuso sus leyes en la región del Vaupés, palabra que parece derivada de Boupé, antiguo jefe tariana que consolidó la hegemonía de su pueblo en guerras contra las tribus vecinas.

Entre todas las tribus del Vaupés, la tariana se distingue por sus numerosas leyendas y porque, al parecer, de esta cultura fue que irradió el culto de Yurupary, imponiéndose sobre las creencias primitivas que antes prevalecían en esta zona. (Orjuela 1993, 27)

El mismo Orjuela procura definirnos desde el campo literario el Yurupary de esta manera:

La leyenda de Yurupary, tal como ha llegado hasta el presente, constituye en su dimensión de epopeya, el texto más importante que se ha rescatado de la literatura indígena suramericana $[\ldots]$

Aunque Yurupary es un mito prehispánico cuya vigencia puede tener miles de años, la historia del recobro de la leyenda para la literatura amerindia se inicia a fines del siglo XIX, cuando se abre para la investigación etnográfica y antropológica la zona del Vaupés. [...]

En Yurupary su dimensión poética es incuestionable, como también lo es su carácter de mito, leyenda o epopeya de los indios Tariana del Vaupés. (Orjuela 1993, 5 y 23)

Para los investigadores literarios como vemos, ha sido muy difícil clasificar este texto y así se ha presentado como leyenda, mito precolombino, epopeya, poema, ateniéndose al texto escrito de Stradelli; sin embargo, al proceder así se omiten otras dimensiones del texto igualmente importantes, lo que molesta seguramente a los antropólogos, por cuanto el relato de Yuruparí, en verdad, implica otras dimensiones textuales no necesariamente lingüísticas, como el rito, la danza, la música, la parafernalia de máscaras y objetos simbólicos por ejemplo; para decirlo en palabras de Martin Lienhard, es un texto "multimedial". Por otro lado, al hacer parte de una tradición oral, mitológica, compartida por muchos pueblos amazónicos, donde ha tenido una vigencia centenaria, es claro que no existe una versión única autorizada del mito; el mito vivo se actualiza, se reactualiza en cada ocasión y sufre con el tiempo transformaciones, adaptaciones, reinterpretaciones, y aún en el espacio de su dominancia se pueden encontrar variantes del mito de acuerdo con cada grupo étnico, y según un largo proceso de encuentro y desencuentro entre las sociedades, de negociaciones en el plano de lo simbólico, de agresiones y de respuestas defensivas. 
En su primera investigación sobre el Yurupari, Orjuela tuvo en cuenta la existencia de variantes, tukano y arawak del mito, pero finalmente el texto que prevalece es la versión de Stradelli; el investigador nos enuncia una serie de posibilidades de interpretación del texto así:

De estas investigaciones, y del examen del complejo mítico ritual, determinamos varias posibilidades acerca de las interpretaciones que se le pueden dar a Yurupary, el cual podría considerarse:

a) Un mito religioso-agrícola de carácter cíclico o periódico que celebra las cosechas, la germinación y el crecimiento de los frutos y la fertilidad de la naturaleza.

b) Un ceremonial iniciático por el cual los jóvenes cambian de status y se vinculan enteramente a la sociedad tribal, asegurando así la supervivencia de las instituciones y la vida misma del grupo.

c) Un mito ceremonial encaminado a preservar del incesto a los miembros de la tribu.

d) Un culto de los antepasados que celebra en especial la memoria de un héroe mítico, líder religioso y legislador, cuya presencia se invoca para renovar las creencias en sus leyes y enseñanzas.

e) Un rito secreto masculino cuyo propósito es asegurar el predominio del hombre sobre la mujer en la sociedad indígena.

(Orjuela 1993, 24)

Reichel-Dolmatoff por su parte, resta cualquier mérito a la literatura que se ha escrito sobre el Yuruparí, incluso a la interpretación de Stradelli y sienta a su vez su propia opinión al respecto; "La versión más poética y menos acertada es la de Stradelli”, dice Reichel-Dolmatoff $(1986,199$, Nota 7) téngase en cuenta que el texto del antropólogo es anterior en varios años al primer trabajo de Orjuela.

El nombre de Yuruparí es un término prestado de la lingua Geral, cuya etimología aún no ha sido aclarada satisfactoriamente. Se trata de un complejo ceremonial que, ya desde el siglo pasado, ha llamado la atención de etnólogos, misioneros y viajeros y sobre el cual existe una abundante literatura. Sin embargo, en buena parte se trata de especulaciones que solo raras veces parecen acercarse a la realidad, es decir a las ideaciones formuladas por los mismos indígenas acerca de esta ceremonia. Así, el Yurupary se ha interpretado por los diversos autores como la conmemoración de un héroe cultural, como un rito de fertilidad, como orgía diabólica y aún como una leyenda romántica y llena de poesía. A grandes rasgos, la "fiesta de Yuruparî" se ha descrito como una ceremonia exclusiva de los hombres iniciados, durante la cual se tocan grandes flautas que las mujeres no deben ver ni oír, bajo pena de graves castigos. Al mismo tiempo, para dicho evento los hombres traen grandes cantidades de frutas silvestres; se organiza una procesión o baile; los participantes llevan máscaras y a veces la ceremonia se combina con la iniciación de un grupo de jóvenes, que de tal modo son incorporados a una sociedad secreta. Todo viajero por el Vaupés ha oído hablar del Yuruparí, ceremonia que siempre ha preocupado la imaginación de los misioneros y caucheros, y sobre cuyo significado se han formado las teorías más diversas. Ya que evidentemente se trata de un 
ritual bastante complejo, cargado de un simbolismo erótico muy marcado, los mismos indígenas, frente a tantas preguntas incómodas, muchas veces optan por contestar simplemente que "el Yuruparí es el diablo", o cualquier respuesta al estilo, explicación que satisface a muchos pero que desorienta a otros que quisieran saber más. (ReichelDolmatoff 1986, 198-199)

Milagros Palma, quien hace una interpretación ambigua o por lo menos contradictoria de la mitología indígena al forzar el trabajo de interpretación antropológico con una maniquea perspectiva feminista a ultranza, también contribuye a desorientar el sentido o el significado de Yuruparí, al acumular una vasta serie de definiciones de lo que este es, representa o simboliza:

El mundo de los letuama nació al mismo tiempo que Yuruparí, el principio de la creación. La palabra Yuruparí fue introducida por los colonos de la región amazónica, para denominar el concepto de divinidad entre la gente de la selva, simbolizada a través de flautas. Estas representan el principio fecundo de la vida, que se materializa en la matriz de la dueña del mundo, de donde provienen los Ayas. Yuruparí simboliza el principio de la vida en su expresión más abstracta. Yuruparí es la fuerza cósmica que asegura la armonía del ritmo cotidiano del mundo, generando la dinámica que entretiene la vida $[\ldots]$

Los letuamas hablan de una morada de la divinidad, ubicada en el gran río del mundo, donde se zambulle el sol al atardecer. Al comienzo Yuruparí cargaba en su cabeza al mundo y así se comía a la gente, por eso, los Ayas se preguntaron un buen día.

-¿Por qué será que la gente se pierde?

Los cuatro señores descubrieron lo que sucedía con la gente. Entonces, bajo forma de jaguar, se fueron al comienzo del mundo, a la propia cepa del mundo y allí miraron a la divinidad. Ellos huyeron aterrados al ver que Yuruparí hablaba por las manos. Una voz fuerte salía de la mano derecha y una más bajita salía de su mano izquierda. Pero el susto de los Ayas fue más grande, cuando oyeron el vozarrón que provenía del corazón de la divinidad. Entonces comprendieron el peligro y capturaron a Yuruparí cuando asomó la cabeza a la superficie de las aguas del gran río del mundo. Yuruparí era anaconda y vivía en las profundidades de las aguas, pero al emerger aparecía como gente. [...]

Los Ayas sufrían viendo morir a la gente, en medio de terribles dolores y para salvar a la gente decidieron quemar a Yuruparí. [...] Cuenta la historia que de las cenizas nació una caña, con la cual se hacen las flautas de Yuruparí. La caña es la imagen de la divinidad, que purificada por el fuego ascendió para conducir el mundo desde arriba. (Palma, 1982, 73 y ss.)

Contrasta esta re-narración de una de las muchas versiones del mito de Yurupari, aparentemente neutral, donde la voz antropológica se confunde literariamente con la voz del posible narrador indígena, con la toma de posición de la autora en la interpretación del hecho socio-antropológico aplicándole una perspectiva occidental.

Los mitos aborígenes... revelan que la violencia es el fundamento de la creación de la mujer. Evocando el despojo del cual es víctima la mujer, ellos ilustran el aspecto social de la construcción de la feminidad por medio de la intervención de los hombres... 
Los relatos míticos nos permitirán ver "cómo se acapara de manera sutil y permanente el espíritu de las mujeres" y cómo los hombres promueven los fantasmas de dominación del mundo femenino. [...]

Según los mitos aborígenes del Amazonas la reducción de la mujer, su sometimiento, ha resultado de grandes enfrentamientos una vez vencida su resistencia... Con el aniquilamiento de la oposición femenina, se alzan los símbolos del poder supremo.

La imagen de la mujer mutilada traduce, en los espacios oscuros del inconsciente, su estado de impotencia. Una vez destruida su identidad original, la mujer se vuelve un ser incompleto. Gracias a esta operación castradora se perpetúa la especie humana: el destino de la mujer es la reproducción.

Los mitos muestran que el engaño del hombre es una manera de someter a la mujer. La violencia física y moral es el recurso necesario para vencer cualquier resistencia. Con la violencia se construye la irremediable cultura de la violación. (Palma 1986/1992, 9-10)

Mi opinión al respecto es que Milagros Palma como muchos otros, cometen un gran error al pretender interpretar los mitos amerindios a partir de perspectivas, teorías y categorías eurocéntricas, tal vez válidas para analizar las problemáticas propias de la sociedad occidental, pero de ninguna manera pertinentes para aproximarse respetuosamente a la comprensión de sociedades otras; pero no sólo se trata de un error epistémico, sino que procediendo de esta manera, se le da continuidad al ejercicio de una verdadera violencia simbólica semejante a la ejercida por los clérigos extirpadores de idolatrías, que en su afán proselitista veían en el culto, en las ceremonias, en los ritos y en los mitos indígenas productos del demonio propios de sociedades bárbaras y atrasadas.

Otro tanto podría afirmarse de interpretaciones delirantes procedentes de esa nueva gnosis light postmoderna, en donde se mezclan libremente los viajes astrales con el consumo de yagé, la Atlántida y los extraterrestres, la teoría de la relatividad y el ocultismo, para explicar las civilizaciones amerindias (Vesga Núñez 2003).

Para Levi-strauss, el mito de Yuruparí, en conjunto con otros textos sabios y esotéricos procedentes de los pueblos suramericanos, sería el testimonio de una autentica civilización compleja y avanzada común a los pueblos de la Amazonía que precedió al estado de fragmentación y desestructuración social que conocemos en la actualidad.

Se conocen múltiples variantes de este mito, algunas considerablemente desarrolladas. No las examinaremos en detalle, pues parecen participar de otro género mitológico que los relatos populares, relativamente homogéneos en tono e inspiración, que reunimos aquí para servir de materia a nuestra indagación. Al parecer, algunos investigadores ya antiguos, en primer lugar Barbosa Rodríguez, Amorim, Stradelli, consiguieron aun recoger en la cuenca amazónica textos esotéricos pertenecientes a una tradición sabia, y así comparables a los obtenidos más recientemente por Nimuendaju y Cadogan entre los Guaraní meridionales. Por desgracia, no sabemos nada, o casi, sobre 
las antiguas sociedades indígenas que otrora ocuparan el Amazonas medio y bajo. El testimonio lacónico de Orellana, que descendió por el río hasta el estuario en 1541 1542, y sobre todo la existencia de tradiciones orales que su extrema complejidad y el artificio que rige su composición, el tono místico, permiten atribuir a escuelas de sabios y de eruditos, hablan a favor de un nivel de organización política, social y religiosa muy por encima de todo lo que desde entonces se ha podido observar. El estudio de estos inapreciables documentos, vestigios de una auténtica civilización común a la totalidad de la cuenca amazónica, requeriría por sí mismo un volumen, y exigiría el recurso a métodos especiales en que la filología y la arqueología (una y otra todavía en el limbo, por lo que toca a América Tropical) debiera contribuir. Acaso se logre esto un día.

(Lévi-Strauss 1987, p 226-227)

Quisiera a manera de conclusión presentar una serie de puntualizaciones a propósito de las lecturas del Yuruparí y mi posición personal al respecto.

El Yuruparí como hemos tenido la oportunidad de ver es realmente un complejo mítico ritual que integra relato oral, danza y música ceremonial, ritual de transición, objetos y ornamentos, y en últimas reactualización de un mito ancestral por medio del cual se instauraron leyes relativas al comportamiento sexual de hombres y mujeres, jóvenes y adultos, y normas de articulación de unos grupos sociales con otros; en él se integra también un saber y unos códigos relativos al mundo de los astros, su relación con ciclos estacionales y por lo tanto con las actividades económicas de los grupos, la caza, la pesca, la agricultura. El Yuruparí como todo mito vivo instituye una cosmovisión, e integra una dimensión praxiológica o cosmoacción, una dimensión cognitiva o conjunto de saberes sobre los mundos natural, social y sobrenatural, y establece conjuntos de valores relativos a esas dimensiones.

Este complejo mítico es compartido, con variantes, por muchos pueblos amazónicos, tiene una vigencia actual y se tienen noticias de él por los viajeros y misioneros al menos desde el siglo XVIII. El texto de Roberto y Stradelli es sólo una versión, del texto de la tradición oral, llevado a la escritura por un sabio indígena, seguramente con unas motivaciones particulares, en unas circunstancias de tiempo y lugar específicas, pero eso no significa que sea ni la única, ni la mejor, ni la más exacta, versión del mito.

Una de las características de la Amazonía, es que ha sido desde tiempos inmemoriales una zona de confluencia, de contacto y de transacciones entre múltiples pueblos, lenguas y culturas, el hecho mismo de que sea compartido, este complejo mítico ritual, por muchos pueblos ya lo signa con la impronta de la interculturalidad, de ser un producto 
heterogéneo cultural y lingüísticamente. El trabajo de recopilación, transcripción y unificación de Max Roberto, valiéndose de muchos informantes lo constata igualmente, y para esta versión específica, habría que agregar la labor de traducción al italiano efectuada por Stradelli y sus distintas versiones del italiano al español. No debe olvidarse sin embargo que ya otros antropólogos y viajeros para la misma época tenían sus propias versiones escritas y con posterioridad los antropólogos han acopiado nuevas variantes en épocas más recientes.

La relación que se ha establecido por parte de algunos investigadores entre el texto de Yuruparí y textos más antiguos que han adquirido por derecho propio un prestigio académico como el Popol-Vuh o el drama de Ollantay, no me parece conveniente ni convincente; los paralelos que se establecen entre las obras son más bien accesorios y no tocan el fondo de sus contenidos, desarrollos, temáticas y estructuras; ni siquiera se puede afirmar que el Yuruparí sea un mito precolombino; entiendo que hay un interés de los investigadores por dotar el texto de una genealogía prestigiosa entre las letras amerindias, un afán de exaltar lo amerindio como el fundamento de las letras nacionales y la búsqueda en este acervo de una obra "representativa" de las mismas; pero como se ha visto las dimensiones espacio-geográficas y temporales del mismo mito nada tienen que ver con las naciones, los Estados y sus fronteras en el mundo latinoamericano. La historia y la condición actual de muchos pueblos amerindios deja fuera de base cualquier pretensión de apropiación nacionalista de sus productos culturales; piénsese por ejemplo en los Wayúu, cuyos territorios ancestrales se extienden entre Colombia y Venezuela, los Cuna, Embera y Waunana, hoy en día presentes unos en territorio Panameño y Colombiano y los otros entre Colombia y Ecuador; en el caso Amazónico se presenta una situación similar al ser este un territorio compartido por Colombia, Perú, Ecuador, Brasil, y Venezuela, ¿qué sentido tiene entonces decir que este mito de este pueblo es Brasilero, Peruano o Colombiano?

Por otra parte, creo que sí se pueden desentrañar substratos míticos amerindios que han ejercido una acción transformadora sobre las estructuras sintácticas y semánticas de las obras literarias de factura occidental de autores con nombre conocido entre la literatura colombiana, pero este es un campo que muy recientemente empieza a ser explorado, en mi caso particular creo haberlo demostrado para novelas como La vorágine en relación

Poligramas 36, segundo semestre 2011, ISSN 0120-4130. 
con los mitos amazónicos, y para la novela Andágueda respecto de los mitos y cosmovisión de los Embera en el occidente colombiano; otros trabajos han demostrado la importante carga del universo mítico Wayúu en la configuración de la obra de García Márquez, y es de esperarse que trabajos semejantes aplicados a otras obras y autores, nos revelen que la literatura colombiana no sólo se ha nutrido de la tradición occidental.

Finalmente, me parece que ya es tiempo, de llamar la atención de los investigadores, literatos y público en general, sobre la importancia de reconocer nuestra inmensa riqueza cultural y lingüística, para que las literaturas indígenas y las obras de autores indígenas empiecen a tener un más amplio reconocimiento en el campo de la literatura nacional y dejen de ser vistas como productos exóticos y marginales; a partir de las recopilaciones de mitos y leyendas realizadas por antropólogos, folclorólogos y otros especialistas, el corpus de textos amerindios es bien significativo y en ellos se puede encontrar una profundidad filosófica, espiritual, ética y estética, una fuente de sabidurías ancestrales; a este corpus, habría que agregar, los textos escritos por los mismo líderes e intelectuales indígenas, textos heterogéneos en donde se conjugan el mito y la historia, lo biográfico y lo etnográfico, donde se aboga por el reconocimiento del derecho de la diferencia, el diálogo y el entendimiento intercultural.

\section{Bibilografía}

Anónimo (Prólogo de Roberto Pineda Camacho). El libro rojo del Putumayo. Precedido de una introducción sobre el verdadero escándalo de las atrocidades del Putumayo. Bogotá. Edit Planeta. 1995

Arango Ferrer Javier. Dioses, brujos y héroes precolombinos. En revista Mito. Bogotá. Año V. N 26. 1959

Arango Ferrer Javier. Raíz y desarrollo de la literatura colombiana. Bogotá Ediciones Lerner, 1965. (Historia Extensa de Colombia, XIX)

Arango Jesús Cano. Mitos leyendas y dioses chibchas. Manizales. Imp. Departamental. s.f.

Ayala Poveda Fernando. Manual de Literatura Colombiana. Bogotá. Educar. 1994. $6^{\text {a }}$ edic. 
Becerra Cano Margarita. En memoria del abuelo sabedor Mru Púu, una voz tukano del Vaupés. Revista Antípoda No 5 Julio Diciembre de 2007. Pp31-50

Bernal Granados Carlos. El mito de Yurupary. En Bernal Granados carlos et al. Momentos de la literatura colombiana: Encuentro de dos culturas Timo I. Bogotá. Universidad Santo Tomás. Siglo XXI 1999. Pp. 32-51

Caicedo de Cajigas Cecilia. Origen de la literatura colombiana: El Yurupary. Pereira. Universidad Tecnológica 1990.

Caicedo de Cajigas Cecilia (Selección y prólogo). Yuruparí (Engendrado de la fruta). Bogotá. Instituto Caro y Cuervo, Fica. 1990.

Campbell Joseph. El héroe de las mil caras. Psicoanálisis del Mito. México. Fondo de Cultura Económica. 1993, 4ª reimp.

Cornejo Polar Antonio. Escribir en el aire. Ensayo sobre la heterogeneidad socio-cultural en las literaturas andinas. Lima-Berkeley. CELAP- Latinoamericana Edit. 2003

Correa R. François. Relatos Míticos Kabiyary. Bogotá. SCC. 1989

Correa R. François. Por el camino de la Anaconda Remedio. Dinámica de la organización social entre los Taiwano del Vaupés. Bogotá. Universidad Nacional, Colciencias. 1996

Correa R. François. Amazonía Amerindia. Territorio de diversidad cultural. En Geografía Humana de colombia. Tomo VII volumen I. Bogotá. Instituto colombiano de Antropología e Historia. 2000

Dominguez Camilo A. Amazonia Colombiana. Visión general. Fondo de Promoción de la Cultura del Banco Popular. Bogotá 1985.

Eliade Mircea. Mito y Realidad. Madrid. Labor 1968.

Franco Jean. (coordination). La vorágine de José Eustacio Rivera, Lo spasos perdidos de Alejo Carpentier. Montpellier. Université Paul Valery. 2002.

Friedemann Nina y Jaime Arocha. Herederos del Jaguar y la Anaconda. Bogotá. Carlos Valencia edit. $1989,1^{\circ}$ reimp.

Gómez Cardona Fabio. Interculturalidad y violencia étnica en la literatura colombiana. Tésis. Bordeaux. Universidad Michel de Montaigne. 2008.

Gómez Cardona Fabio. Emergencia del mito americano en La vorágine. Revista Poligramas. $\mathrm{N}^{\circ} 30$ Universidad del Valle. 2009 
Guzman Antonio (Miru Púu)- Masá Bëhkë Yurupary. Mito Tukano del Origen del hombre. Versión al español Antonio Guzmán. Compilador y editor Ariel José James. Bogotá. Ediciones Zahir. 2003.

Koch-Grumber Theodor. Dos años entre los indios. Editorial Universidad Nacional. Bogotá. 1995 (2 volúmenes)

Levi-Strauss Claude. Mitológicas II. De la miel a las cenizas. México Fondo de cultura Económica. 1987 Tercera reimpresión.

Lienhard Martin. La voz y su huella. Escritura y conflicto étnico y social en América Latina: 1492-1988. La Habana. Casa de las Américas. 1990.

Literatura quechua. Edición Prólogo y cronología de Edmundo Bendezú Aybar. Caracas. Editorial Ayacucho. 1980

Literatura maya. Compilación y prólogo, Mercedes de la Garza. Cronología de Miguel León Portilla. Caracas. Editorial Ayacucho 1992

Manual de Literatura Colombiana. 2 Tomos. Bogotá. Procultura y Planeta. 1988.

Mazzotti y Zeballos. Asedios a la heterogeneidad cultural. Libro de homenaje a Antonio Cornejo Polar. Philadelphia. Asociación internacional de Peruanistas. 1996

Moreno Blanco Juan. La cepa de las palabras. Ensayo sobre la relacióndel Universo Imaginario Wayúu y la obra de Gabriel García Márquez. Kassel. Edic. Reichenberger. 2002

Moreno Blanco Juan. Gabriel García Márquez. Littérature et Interculturalité. Thèse. Bordeaux. Université Michel de Montaigen Bordeaux 3. 2004.

Niño Hugo (compilador). Literatura de Colombia Aborigen. Bogotá. Instituto Colombiano de Cultura. 1978.

Ordóñez Vila Monserrat. (compilación). La Vorágine: Textos Críticos. Bogotá. Alianza Editorial.. 1987

Orjuela Héctor H. Yurupary. Yurupary: Epopeya indígena suramericana. En Thesaurus, XXXVII, 1982, pp.105-119.

Orjuela Héctor H. Yurupary: Mito, leyenda y epopeya del Vaupés. Bogotá. Instituto Caro y Cuervo. 1983

Orjuela Héctor H. Yurupary. El Popol-Vuh suramericano. Traducción española de Susana Salessi. Edición y estudio de Héctor Orjuela. Bogotá. Editorial Kelly. 1993 
Osorio Betty. El mito de Yurupary: Memoria ancestral como resistencia étnica. Revista de Estudios Sociales N²3, abril de 2006, 105-111

Palma Milagros. Los viajeros de la Gran Anaconda. Managua. Edit. América Nuestra. 1984.

Palma Milagros. La mujer es puro cuento. Feminidad aborigen y mestiza. Bogotá. Tercer mundo editores. 1992. $1^{\text {a }}$ edición de 1986.

Palma Milagros et Feuillet Claude. Le ventre de la grande femme de l'Amazonie. Les Ulis. Côte Femme Edit. 1986

Peña Gutierrez Isaías. Manual de Literatura Latinoamericana. Bogotá. Educar. 1992. $3^{\text {a }}$ edic.

Pérez Trinidad. (recopilación y prólogo). Recopilación de textos sobre tres novelas ejemplares. La Habana. Casa de las Américas. 1971. 1er. Seminario internacional de etnohistoria del norte del Ecuador y el Sur de Colombia.

Pineda Camacho Roberto. La etnohistoria en Colombia: un balance etnográfico. 19401994. En Barona y Zuluaga. Memorias

Posada Rodríguez Elsa Cristina. Oralidades y Escrituras en el Amazonas colombiano. Tesis de Maestría en Literatura Latinoamericana. Pontificia Universidad Javeriana. Bogotá. 2009

Rank Otto. El mito del nacimiento del héroe. Buenos Airs. Paidos. 1961.

Reichel-Dolmatoff Gerardo. Yurupari: Studies of an Amazonian foundation myth. Cambridge. Mass. Harvard University Press. 1966

Reichel-Dolmatoff Gerardo y Alicia. Estudios antropológicos. Bogotá. Instituto Colombiano de Cultura 1977

Reichel-Dolmatoff Gerardo. Desana. Simbolismo de los indios Tukano del Vaupés. Procultura. Bogotá. 1986.

Rivera José Eustacio. La Vorágine. Con prólogo y cronología de Juan Loveluck. Caracas. Edit. Ayacucho. 1976

Rodríguez de Montes María Luisa. Muestra de Literatura oral en Leticia. Amazonas. BogotáInstituto Caro y Cuervo. 1981.

Sedlácková Renata. El Mito amazónico de Yurupary como obra literaria. Brno. Universidad Masryk. 2000 
http://www.premioibam.cz/documentos/6taedicion/1erPremioVI_RenataSedlackova.pdf (Ultima consulta enero de 2011)

Stradelli, Ermanno, conde. Yuruparí; Traducción Beatriz Alzate Ángel; Introducción y notas de Roberto Pineda Camacho y Beatriz Alzate Angel. Bogotá. Panamericana Editorial. 2004

Valencia Solanilla César. Las enseñanzas de Yuruparí. Revista Ciencias Humanas № 21. Universidad Tecnológica de Pereira 2000

Vásquez Juan Adolfo. Literaturas Indígenas de América. Introducción a su estudio. Barcelona. Edit. Azul. 1999

Vesga Núñez Omar. Yurupary, El hijo de las Pléyades, que fundó una nación en el Vaupés. Breve estudio comparado. Bogotá. Sin dato editorial. 2003. 